\title{
Effects of astaxanthin on dinitrofluorobenzene-induced contact dermatitis in mice
}

\author{
HYUNGWOO KIM ${ }^{1 *}$, YONG-TAE AHN ${ }^{2 *}$, GUEM SAN LEE ${ }^{3}$, SU IN CHO ${ }^{1}$, JONG-MYOUNG KIM ${ }^{4}$, \\ CHU LEE ${ }^{5}$, BYUNG KWAN LIM ${ }^{6}$, SEONG-A JU ${ }^{7}$ and WON GUN AN ${ }^{1}$ \\ ${ }^{1}$ Division of Pharmacology, School of Korean Medicine, Pusan National University, Yangsan 626-870; \\ ${ }^{2}$ Department of Biomedical Science, Kyungdong University, Goseong-gun, Gangwon-do 219-832; ${ }^{3}$ Oriental Medicine, \\ Woosuk University, Jeonju 565-701; ${ }^{4}$ Department of Marine Biomaterials and Aquaculture, Pukyong National University, \\ Busan 608-737; ${ }^{5}$ Aquaculture Industry Division, National Fisheries Research and Development Institute, Gangneung, \\ Gangwon-do 210-861; ${ }^{6}$ Department of Visual Optics, Kyungdong University, Goseong-gun, Gangwon-do 219-832; \\ ${ }^{7}$ Biomedical Research Center, Ulsan University Hospital, College of Medicine, \\ University of Ulsan, Ulsan 682-714, Republic of Korea
}

Received July 11, 2014; Accepted March 10, 2015

DOI: $10.3892 / \mathrm{mmr} .2015 .3892$

\begin{abstract}
Astaxanthin (AST) is known to exhibit antioxidative and antitumor properties, therefore, the present study investigated its other potential medical applications. AST was observed to exhibit anti-allergic and anti-inflammatory effects in a dinitrofluorobenzene (DNFB)-induced contact dermatitis (CD) mouse model and RBL-2H3 cell lines. The topical application of AST effectively inhibited the enlargement of ear thickness and increase in weight, which occurred following repeated application of DNFB. Furthermore, topical application of different concentrations of AST inhibited inflammatory hyperplasia, edema, spongiosis, and the infiltration of mononuclear cells and mast cells in the ear tissue. In addition, the levels of TNF- $\alpha$ and IFN- $\gamma$ produced were decreased by application of AST in vivo, and treatment of RBL-2H3 cells with AST inhibited the release of histamine and $\beta$-hexosaminidase in vitro. Taken together, these data suggested that AST may be used to treat patients with allergic skin diseases through a mechanism, which may be associated with that involved in anti-inflammatory or anti-allergic activities.
\end{abstract}

Correspondence to: Professor Won Gun An, Division of Pharmacology, School of Korean Medicine, Pusan National University, 49 Beon-gil Busandaehak-ro, Yangsan 626-870, Republic of Korea E-mail:wgan@pusan.ac.kr

*Contributed equally

Key words: astaxanthin, dinitrofluorobenzene, anti-inflammatory, contact dermatitis, anti-allergic

\section{Introduction}

Contact dermatitis (CD), one of the most common types of skin disorder in developed countries, is an inflammatory skin disease, which is induced by repeated skin contact with a low molecular weight chemical, termed a hapten (1). The onset of CD is predominantly due to the recruitment of chemical-specific $\mathrm{CD}^{+} \mathrm{T}$ cells (2). In addition, $\mathrm{CD}^{+} \mathrm{T}$ helper (Th) 1 and Th17 contribute to the extension of the inflammatory reaction by releasing pro-inflammatory cytokines, including IFN- $\gamma$ and TNF- $\alpha$, which activate cells within the skin $(2,3)$. In mouse models, repeated antigen application results in an immediate-type response $30 \mathrm{~min}$ after antigen exposure, demonstrating the involvement of mast cells in the immediate-type response $(4,5)$.

Mast cells are commonly found at sites of CD and are involved in immediate-type allergic reactions and inflammation (6). It is well established that immediate-type allergic reactions are markedly reduced in the absence of mast cells, demonstrated using mouse models of mast cell deficiency (7). The degranulation of mast cells induces the secretion of bio-active substances, including histamine, cytokines and chemokines (8). Cytokines, particularly TNF- $\alpha$, are released in late-phase allergic reactions and inflammation via the recruitment of inflammatory cells (9).

It has been reported that cross-talking between oxidative stress and inflammation causes cutaneous damage in CD (10). There is increasing evidence that oxidative stress accentuates the immunological damage in CD $(11,12)$, and certain antioxidants have anti-inflammatory and anti-allergic effects in irritant or allergic CD $(13,14)$. Previously, it was reported that dietary carotenoids significantly inhibited ear swelling and reduced the levels of TNF- $\alpha$ and histamine in dinitrofluorobenzene (DNFB)-treated mice (15).

Astaxanthin (3,3'-dihydroxy- $\beta, \beta$-carotene-4,4'-dione; AST) is a keto-carotenoid and a type of xanthophyll, which are found in microalgae, fungi, complex plants, seafood, flamingos 
and quail (16). AST has been investigated for its potential medical applications as it has antioxidative and antitumor properties $(17,18)$. AST is known to have anti-inflammatory activities in endotoxin-induced uveitis (19) and laser-induced choroidal neovascularization (20).

Based on these previous observations, the present study evaluated the anti-allergic and anti-inflammatory effects of AST by using mouse model of CD in vivo and the RBL-2H3 mast cell-like leukemia cell line in vitro. It was hypothesized that AST treatment may serve as a therapeutic approach in patients with $\mathrm{CD}$, as an alternative to the use of steroids.

\section{Materials and methods}

Chemicals and reagents. The reagents, 1-fluoro-2,4-dinitrofluorobenzene (dinitrofluorobenzene; DNFB), dimethyl sulfoxide (DMSO), dexamethasone (DEX), phorbol 12-myristate 13-acetate (PMA), calcium ionophore A23187, nuclear fast red solution and fetal bovine serum (FBS) were purchased from Sigma-Aldrich (St. Louis, MO, USA). Alcian blue was purchased from Muto Pure Chemical (Tokyo, Japan). Dulbecco's Modified Eagle's Medium (DMEM/high glucose), penicillin and streptomycin were purchased from GE Healthcare (Logan, UT, USA). PrestoBlue cell viability reagent was purchased from Invitrogen Life Technologies (Carlsbad, CA, USA). The Cytometric Bead Array kit was purchased from BD Biosciences (Franklin Lakes, NJ, USA). The histamine assay kit, including -nitrophenyl- $N$-acetyl- $\beta$ -D-glucosaminide was purchased from Oxford Biomedical Research (Rochester Hills, MI, USA).

Preparation of AST. Haematococcus pluvialis CCAP-34/1F (Subitec Gmbh, Stuttgart, Germany) were cultured in Bold's basal medium $(21,22)$, with additional nitrogen $(1 \mathrm{~g} / \mathrm{l})$ for efficient growth, with conditions of $25^{\circ} \mathrm{C}, 160 \mathrm{rpm}$ (incubator rotation), $10 \%$ inoculum, $\mathrm{pH} 7.0$ and $60-70 \mu \mathrm{mol}$ photon. $\mathrm{m}^{-2} . \mathrm{s}^{-1}$ with fluorescent lamps. In order to induce the production of AST and the cyst cells from the vegetative cells, the cell culture (optical density at $650 \mathrm{~nm}, 0.5$ ) were transferred to the medium without nitrogen and cultured at $23^{\circ} \mathrm{C}$ and $300 \mu \mathrm{mol}$ photon. $\mathrm{m}^{-2} \cdot \mathrm{s}^{-1}$ for 15 days. Upon confirming the production of AST, cultured cells $(\sim 4.2 \times 105$ cells $/ \mathrm{ml})$ were collected by centrifugation at $8,000 \mathrm{x} \mathrm{g}, 4^{\circ} \mathrm{C}$ for $5 \mathrm{~min}$, were crushed and mixed with $25 \mathrm{ml}$ acetone in a sonicator (Branson 250, Danbury, CT, USA) and subjected to repeated cold extraction followed by fractionation. Subsequently, concentration of the extract was performed under reduced pressure, extracted with n-hexane, and then washed with water three times. To remove the residual water, $1 \mathrm{~g}$ sodium sulfate anhydrous was used for extraction of the AST. For the subsequent experiments, the AST was dissolved in $0.01 \%$ DMSO.

Animals. Male balb/c mice (6-weeks-old; 38 mice used) were purchased from Samtaco (Incheon, Korea). The mice were housed under specific pathogen-free conditions with a $12 \mathrm{~h}$ light/dark cycle and free access to standard rodent food and water. All animal experiments were approved by the Animal Care and Use Committee of Pusan National University (Yangsan, Republic of Korea) and performed, according to institutional guidelines (PNU-2010-00065).
Induction of $C D$ and experimental design. The mice were sensitized by applying $50 \mu \mathrm{l}$ DNFB $(0.1 \%$, v/v) in acetone:olive oil (AOO; 4:1) on the dorsum of each ear for each animal for three consecutive days. At 4 days-post sensitization, $30 \mu 1$ DNFB $(0.2 \%, \mathrm{v} / \mathrm{v})$ in AOO was applied onto the dorsum of each ear every 2 days. The AST was dissolved in AOO and then filtered using a syringe filter $(0.45 \mathrm{~nm}$; Millipore, Billerica, MA, USA), prior to dilution in acetone. The AST was dissolved in olive oil and was then filtered using a syringe filter $(0.45 \mathrm{~nm})$, prior to dilution in acetone. The AST solution at a final concentration of either 0.1 or $1 \mathrm{mg} / \mathrm{ml}$, was applied to the dorsum of each ear every 2 days. All animals, with the exception of the naïve group, were sensitized and challenged with DNFB. The animals in the naïve group were sensitized with vehicle, with subsequent AOO application $(n=6)$. The control animals (CTL group) were sensitized and challenged with DNFB, followed by AOO application $(n=8)$. The AST0-treated animals were sensitized and challenged with DNFB, followed by the application of either $0.1 \mathrm{mg} / \mathrm{ml}$ AST (0.1 AST group; $\mathrm{n}=8$ ) or $1 \mathrm{mg} / \mathrm{ml} \mathrm{AST} \mathrm{(1} \mathrm{AST} \mathrm{group)}$ solution $(n=8)$. The DEX-treated animals (DEX group) were sensitized and challenged with DNFB, followed by application of $2.5 \mathrm{mg} / \mathrm{ml}$ dexamethasone, and were used as a positive control. Sensitization applications were performed on days 1,2 and 3, and challenge applications were performed on days 7, 9, 11 and 13. The naïve group was treated with AOO in the same manner. In the AST and DEX groups, the AST or DEX were applied on days 8, 10, 12 and 14. All animals were sacrificed by cervical dislocation on day 15 . The experimental design is shown in Fig. 1.

Measurement of ear thicknesses and weight. The mice were anesthetized with $30 \mathrm{mg} / \mathrm{kg}$ of zoletil (Virbac, Carros, France), and the thicknesses of the right ear of each mouse was measured using vernier calipers (Mitutoyo Corporation, Tokyo, Japan) at the end of the experiment. The weights of left ear pieces ( $5 \mathrm{~mm}$ in diameter), which were resected by dermal punch (HB 925; Hebu Medical GmbH, Badstraße, Germany) and were embedded in paraffin, were also measured.

Histopathological examination. Following measurement of the ear thickness and weights, the ear tissues were resected and paraffin-embeded. The sections were stained with hematoxylin and eosin (HE) for histopathological observation, including the evaluation of immune cell infiltration and spongiosis. Alcian blue staining was also used to evaluate the distribution of mast cells and nuclear fast red solution (Sigma-Alrich) was used for counter staining. The stained tissues were observed using a light microscope.

Measurement of cytokine production. At the end of the experiment, the resected ear tissues were lysed and homogenized with protein extraction solution (Intron bio, Daejeon, Korea) using a bullet blender (Next advance, Averill Park, NY, USA), to obtain the tissue lysates. Subsequently $50 \mathrm{~g}$ of the lysates were used to measure the levels of IFN- $\gamma \mathrm{g}$ and TNF- $\alpha$. The cytokine levels were measured using a cytometric bead array kit (BD Biosciences). All experimental procedures were performed according to the manufacturer's instructions. 


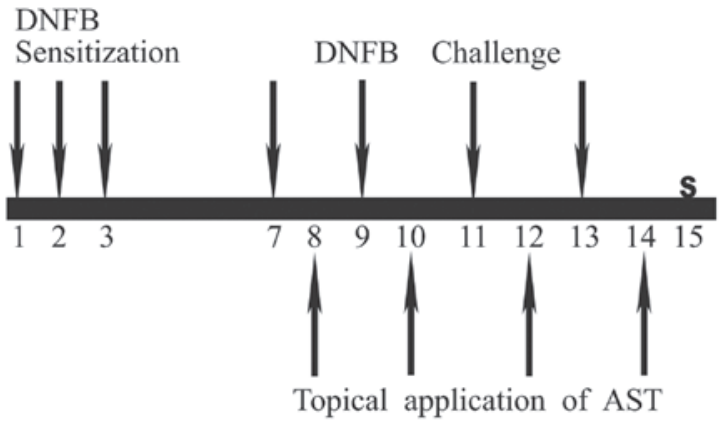

Figure 1. Experimental design for animal investigations. The experimental groups, with the exception of the naïve group, were sensitized by application of DNFB on days 1,2 and 3. They were challenged on days 7, 9, 11 and 13 . The naïve group was treated with acetone:olive oil, in the same manner. In the AST and DEX groups AST or DEX were applied on days 8, 10, 12 and 14. All animals were sacrificed (S) on day 15. DNFB, dinitrofluorobenzene; AST, astaxanthinl; DEX, dexamethasone.

Cell culture. The RBL-2H3 cells were purchased from the Korean Cell Line Bank (Seoul, Korea) and grown in DMEM/high glucose, supplemented with $10 \% \mathrm{FBS}$, $100 \mathrm{U} / \mathrm{ml}$ penicillin and $100 \mathrm{~g} / \mathrm{ml}$ streptomycin at $37^{\circ} \mathrm{C}$ in a humidified incubator under $5 \% \mathrm{CO}_{2}$.

Measurement of cell proliferation. The RBL-2H3 cells were plated at a density of $1 \times 10^{5}$ cells/well in a 96-well plate and were left to reach $\sim 70 \%$ confluence. AST $(0-800 \mu \mathrm{g} / \mathrm{ml})$ in complete DMEM was added to each well and the wells were incubated for $2 \mathrm{~h}$ at $37^{\circ} \mathrm{C}$. The effects of AST on cell viability were assessed using $10 \mu 1$ PrestoBlue Cell Viability Reagent (cat. no. A13261; Invitrogen Life Technologies) with $90 \mu 1$ mixture (containing the cells and medium) according to the manufacturer's instructions. Cell viability was measured using a microplate reader (Infinite M200; Tecan Group Ltd.).

Hexosaminidase release assay. The inhibitory effects of AST on the secretion of $\beta$-hexosaminidase from the RBL-2H3 cells were measured using a modification of the method previously described by Matsuda et al (23). Briefly, the RBL-2H3 cells were plated at a density of $2 \times 10^{4}$ cells/well in a 96 -well plate. The cells were incubated overnight for attachment, and were treated with the indicated concentrations of AST for $1 \mathrm{~h}$, prior to stimulation with $50 \mathrm{nM}$ PMA and $1 \mu \mathrm{M} \mathrm{A} 23187$ at $37^{\circ} \mathrm{C}$ for $60 \mathrm{~min}$. Following stimulation, $50 \mu \mathrm{l}$ of each sample was incubated with $50 \mu 11 \mathrm{mM}$ p-nitrophenyl- $N$-acetyl- $\beta$-D-gl ucosaminide dissolved in $0.1 \mathrm{M}$ citrate buffer ( $\mathrm{pH}$ 5.0) in a 96-well plate at $37^{\circ} \mathrm{C}$ for $1 \mathrm{~h}$. The reaction was terminated with $200 \mu \mathrm{l} /$ well $0.1 \mathrm{M}$ carbonate buffer ( $\mathrm{pH} 10.5$ ). The absorbance at $405 \mathrm{~nm}$ was measured using a microplate reader (Tecan 200 Pro, Tecan Group Ltd., Männedorf, Switzerland). The percentage of inhibition of $\beta$-hexosaminidase release was calculated using the following equation: $\beta$-hexosaminidase release $(\%)=$ absorbance of supernatant $/$ (absorbance of supernatant + absorbance of pellet) $\times 100$.

Histamine release assay. The RBL-2H3 cells were plated at a density of $2 \times 10^{4}$ cells/well in a 96 -well plate. The cells were
A

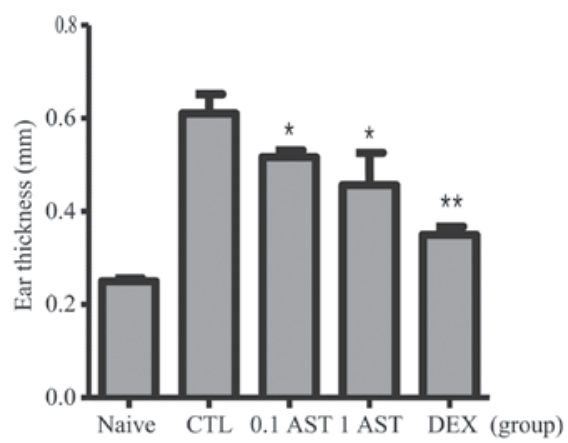

B

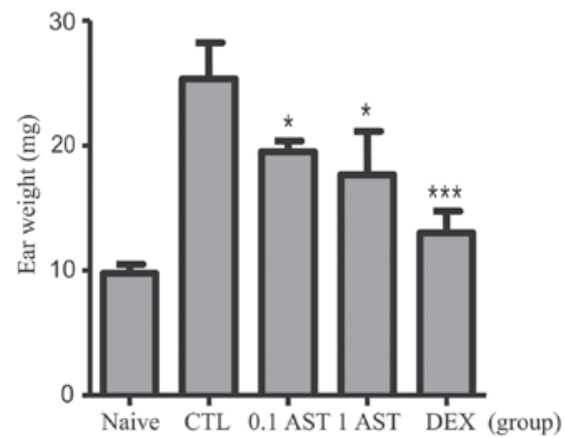

Figure 2. Effects of AST on ear swelling in CD mice. The inhibition of ear swelling by topical application of AST was analyzed by measuring ear thickness and weight on day 15 . The mice in the naïve group were not treated with AST. The CTL group contained CD mice, which were not treated with AST. The 0.1 AST group contained CD mice treated with $0.1 \mathrm{mg} / \mathrm{ml}$ AST. The 1 AST group contained CD mice treated with $1 \mathrm{mg} / \mathrm{ml}$ AST. The DEX group contained CD mice treated with $2.5 \mathrm{mg} / \mathrm{ml} \mathrm{DEX}$ as a positive control. Ear swelling in the $\mathrm{CD}$ mice was measured by (A) ear thicknesses and (B) ear weight. All values are presented as the mean \pm standard deviation. ${ }^{*} \mathrm{P}<0.05$, ${ }^{* *} \mathrm{P}<0.01$ and ${ }^{* * *} \mathrm{P}<0.001$, vs. CTL, analyzed using Student's t-test $(\mathrm{n}=3)$. AST, astaxanthin; CD, contact dermatitis; DEX, dexamethasone; CTL, control.

then incubated overnight in a complete medium, followed by treatment for $1 \mathrm{~h}$ with the indicated concentrations of AST, prior to stimulation with $50 \mathrm{nM}$ PMA and $1 \mu \mathrm{M}$ A23187 at $37^{\circ} \mathrm{C}$ for $30 \mathrm{~min}$. The histamine contents were measured using a histamine detection kit (Oxford Biochemical Research), according to the manufacturer's instructions.

Statistical analysis. All statistical comparisons were made using Student's t-test. SigmaPlot version 11.0 (Systat software, Inc., San Jose, CA, USA) was used for statistical analysis. All data are presented as the mean \pm standard deviation. $\mathrm{P}<0.05$ was considered to indicate a statistically significant difference.

\section{Results}

Effects of AST on ear swelling induction in CD mice. The repeated application of DNFB induced ear swelling, which is a feature of $\mathrm{CD}$. The effects of AST on ear swelling were evaluated by measuring the ear thicknesses (Fig. 2A) and weights (Fig. 2B). In the CTL group, the ear thickness and weights were increased significantly compared with the naïve group. In the Dex group, the ear thickness and weights were decreased markedly compared with the CTL group. However, when different concentrations of AST were applied to the CD mice, following repeated application of DNFB, the increases in the thickness and weight of the mice were effectively 


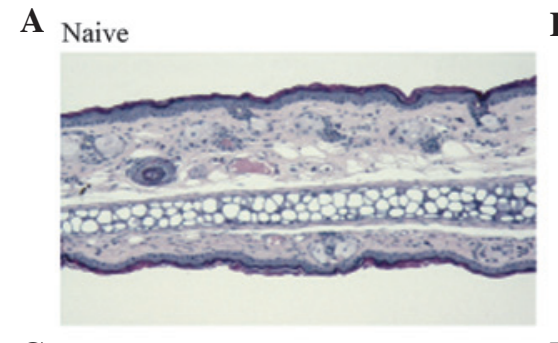

B CTL
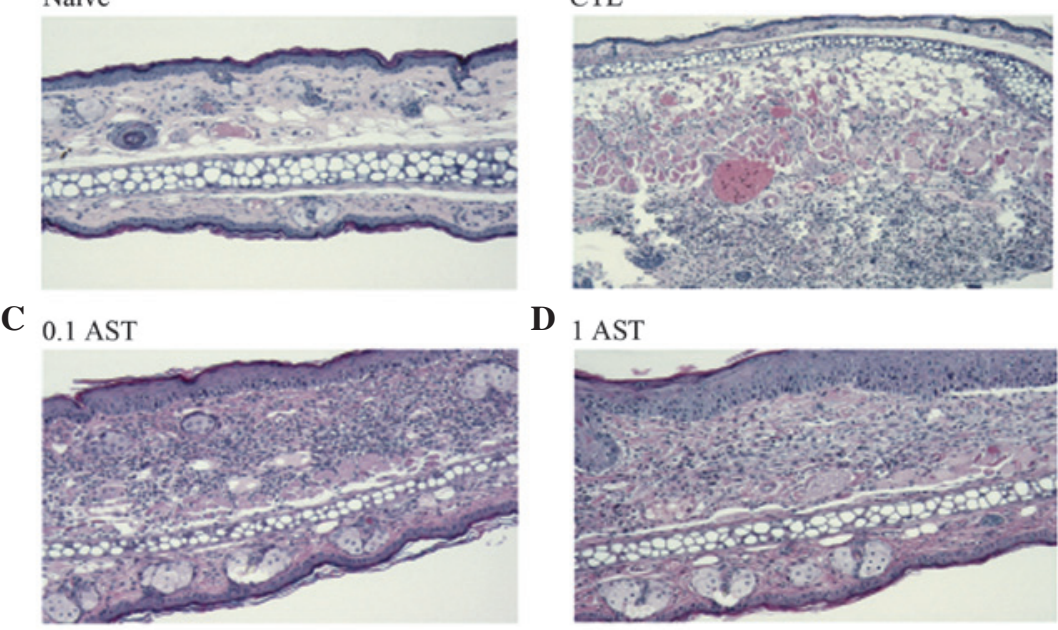

$D_{1 \text { AST }}$

E DEX
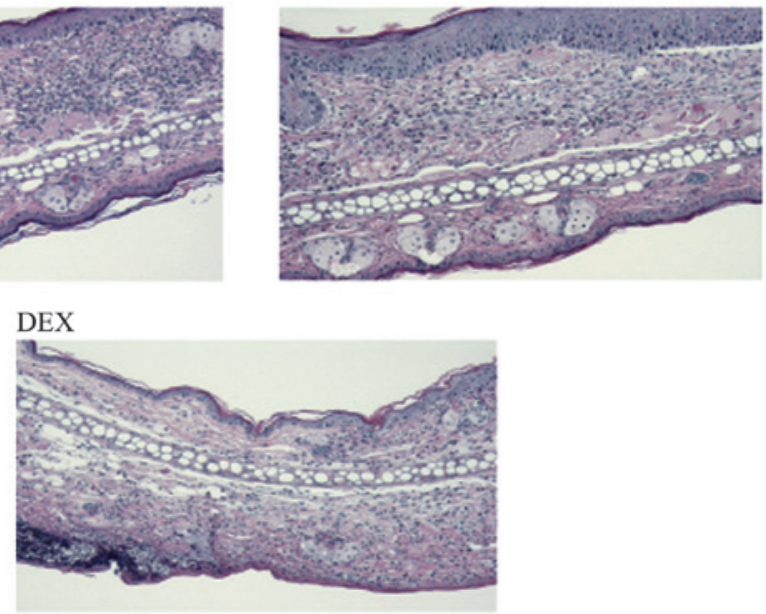

Figure 3. Effects of AST on histopathological changes in CD mice ear tissues. Sections of ear tissues, obtained from normal and CD mice treated with AST or DEX were stained with hematoxylin and eosin and then observed by using a light microscope (magnification, x100). AST, astaxanthin; CD, contact dermatitis; DEX, dexamethasone; CTL, control. (A) Naive group; (B) CTL group; (C) $0.1 \mathrm{mg} / \mathrm{ml}$ of AST treated group; (D) $1 \mathrm{mg} / \mathrm{ml}$ of AST treated group; (E) $2.5 \mathrm{mg} / \mathrm{ml}$ of dexamethasone treated group.

reduced, confirming that AST may decrease the inflammatory reactions.

Effects of AST on histopathological changes of ear tissues in $C D$ mice. In order to determine the histological changes of the $\mathrm{CD}$ mice in response to AST, HE staining was used following DNFB challenge and/or topical AST application to the mice. As shown in Fig. 3, although no abnormal changes were observed in the ear tissues from the naïve group (Fig. 3A), the epidermises from the tissues in the CTL group in Fig. 3B exhibited hyperplasia, severe edema and spongiosis. In addition, a marked infiltration of mononuclear cells was observed in the CTL group (Fig. 3B). However, when the mice in the CTL group were treated with AST, a reduction in the pathophysiological reactions of hyperplasia, edema and spongiosis was observed in the ear tissues (Fig. 3C and D). The DEX group, as a positive control, exhibited infiltration of immune cells (Fig. 3E). Therefore, AST may alleviate inflammatory or allergic reaction in CD mice.

Effects of AST on the levels of IFN- $\gamma$ and TNF- $\alpha$ in CD mice. Pro-inflammatory cytokines, which induce inflammatory reactions were assessed in $\mathrm{CD}$ mice, with or without AST treatment. The repeated application of DNFB in the CTL groups resulted in increased quantities of IFN- $\gamma$ (Fig. 4A) and TNF- $\alpha$ (Fig. 4B) in the ear homogenates. However, treatments with either 0.1 or $1 \mathrm{mg} / \mathrm{ml}$ AST significantly suppressed the augmented level of IFN- $\gamma$ in the CTL group. In addition, treatment with $1 \mathrm{mg} / \mathrm{ml}$ AST significantly repressed the augmented
A

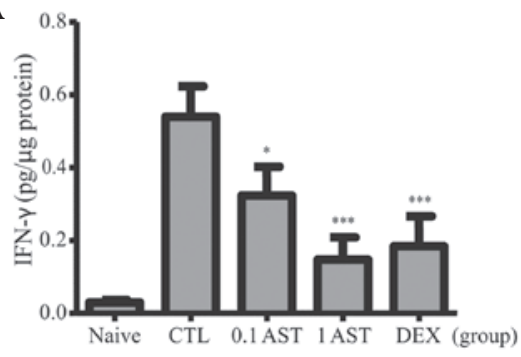

B

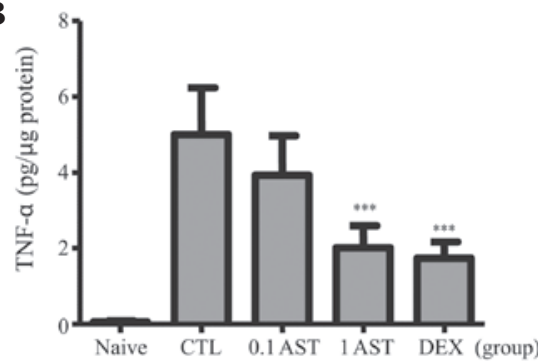

Figure. 4. Effects of AST on the levels of IFN- $\gamma$ and TNF- $\alpha$ in CD mice. Expression levels of (A) IFN- $\gamma$ and (B) TNF- $\alpha$ in the ear tissues of normal mice or from CD mice treated with AST or DEX were measured using a cytometric bead array. All values are presented as the mean \pm standard deviation. ${ }^{*} \mathrm{P}<0.05$ and ${ }^{* * * *} \mathrm{P}<0.001$, vs. CTL, analyzed using Student's t-test $(n=3)$. AST, astaxanthin; CD, contact dermatitis; DEX, dexamethasone; CTL, control.

level of TNF- $\alpha$ (1 AST group in Fig. 4B, whereas, treatment with $0.1 \mathrm{mg} / \mathrm{ml} \mathrm{AST} \mathrm{repressed} \mathrm{the} \mathrm{augmented} \mathrm{level} \mathrm{of} \mathrm{TNF-} \alpha$, but without statistical significance (0.1 AST group in Fig. 4B). 
A Naive

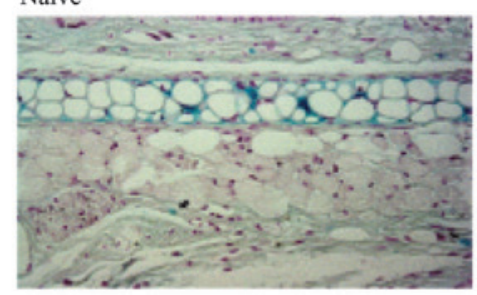

C

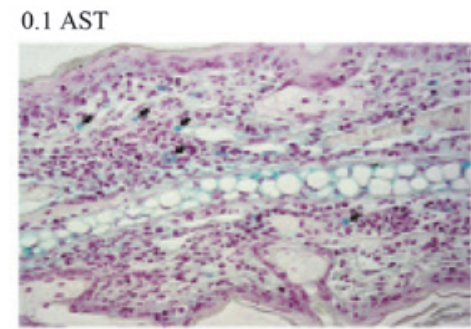

B CTL

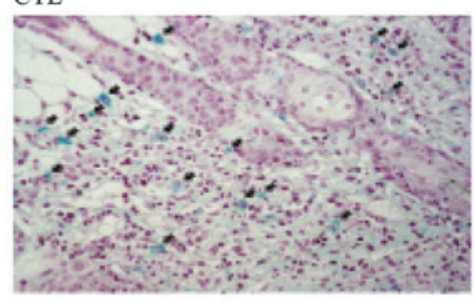

D 1 AST

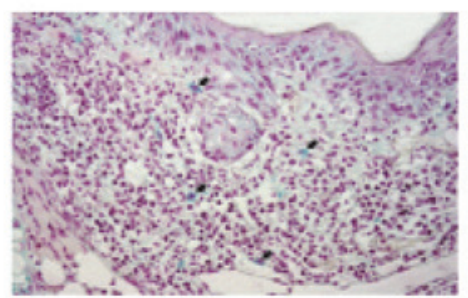

E DEX

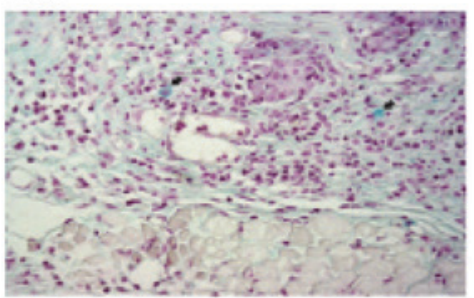

Figure 5. Effects of AST on the density of mast cells in CD mice. Ear tissues from normal mice or from CD mice treated with AST or DEX were stained with alcian blue and then observed using a light microscope (magnification, x200). Filled arrows indicate mast cells. AST, astaxanthin; CD, contact dermatitis; DEX, dexamethasone; CTL, control.(A) Naive group; (B) CTL group; (C) $0.1 \mathrm{mg} / \mathrm{ml}$ of AST treated group; (D) $1 \mathrm{mg} / \mathrm{ml}$ of AST treated group; (E) $2.5 \mathrm{mg} / \mathrm{ml}$ of dexamethasone treated group.

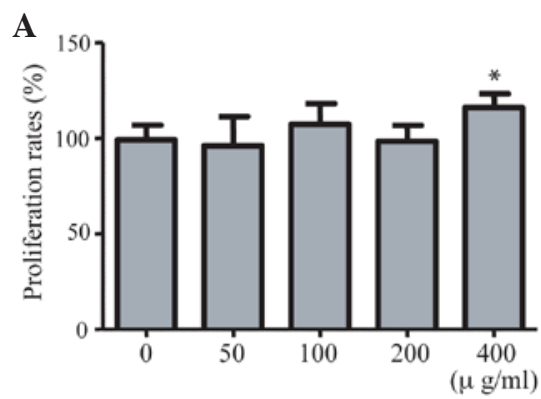

B

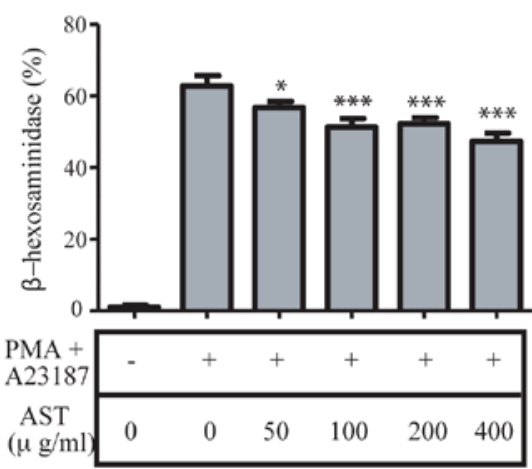

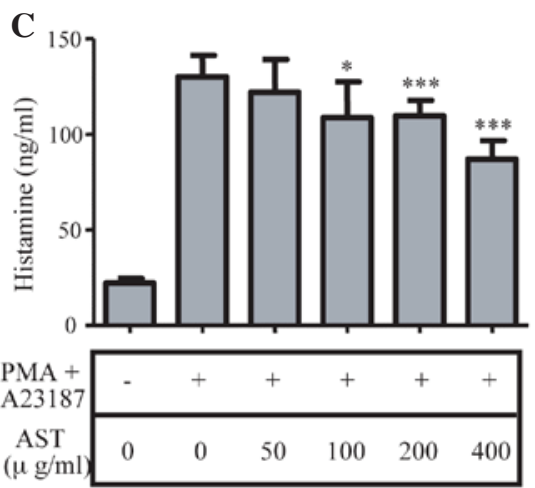

Figure 6. Effects of AST on the degranulation of RBL-2H3 cells. Proliferation rates of the RBL-2H3 cells were measured using a modified MTT method. Release of $\beta$-hexosaminidase and histamine from the RBL-2H3 cells were measured. The (A proliferation rates, (B) secretion of $\beta$-hexosaminidase and (C) secretion of histamine were examined. All values are presented as the mean \pm standard deviation of three independent experiments. ${ }^{*} \mathrm{P}<0.05$ and ${ }^{* * *} \mathrm{P}<0.001$, vs. CTL, analyzed using Student's t-test ( $\mathrm{n}=3$ ). AST, astaxanthin; CD, contact dermatitis; PMA, phorbol 12-myristate 13-acetate; DEX, dexamethasone; CTL, control.

Notably, as shown in Fig. 4, the levels of IFN- $\gamma$ and TNF- $\alpha$ in the 1 AST group exhibited a similar pattern as the DEX group. Thus, these data suggested that AST negatively regulated the IFN- $\gamma$ and TNF- $\alpha$ pro-inflammatory cytokines in the CD mice.

Effects of AST on the density of mast cells in CD mice. Since mast cells are found at sites of CD (6), the present study evaluated them in CD mice (Fig. 5). In the naïve group, few mast cells were observed (Fig. 5A). In the CTL group, a marked increase in the number of mast cells against DNFB (filled arrow in Fig. 5B) was observed in the mice. Treatments with 0.1 and $1 \mathrm{mg} / \mathrm{ml} \mathrm{AST}$ to the mice sensitized to DNFB decreased the density of mast cells compared with the CTL group (Fig. 5C and D). Few mast cells were observed in the DEX group (Fig. 5E). Therefore, AST decreased the density of mast cells in the CD mice, indicating that AST exhibited anti-allergic or inflammatory activities.

Effects of AST on the degranulation of RBL-2H3 cells. Since the degranulation of mast cells causes allergic or inflammatory reactions (9), the present study examined the secretion 
of $\beta$-hexosaminidase and histamine in the RBL-2H3 cells, following stimulation of the cells by PMA and ionophore A23187 to induce inflammation in vitro. As the combination of PMA and A23187 activate cell proliferation to cause inflammation, the present study examined the role of AST in the proliferation of cells. As shown in Fig. 6A, although treatment with $400 \mathrm{~g} / \mathrm{ml}$ AST marginally elevated the proliferation rates of the RBL-2H3 cells, AST did not affect cell proliferation (Fig. 6A). The levels of $\beta$-hexosaminidase were measured, as shown in Fig. 6B. Pretreatment with $>50 \mathrm{~g} / \mathrm{ml}$ AST reduced the levels of $\beta$-hexosaminidase in a dose-dependent manner (Fig. 6B). Similarly, pretreatment with $>100 \mu \mathrm{g} / \mathrm{ml}$ AST also reduced the levels of histamine (Fig. 6C). Therefore, the degranulation of mast cells released $\beta$-hexosaminidase and histamine from the RBL-2H3 cells, and AST had an inhibitory role in their production in vitro.

\section{Discussion}

Physiological stress, air pollution, exposure to chemicals or exposure to ultraviolet (UV) light can enhances the productions of free radicals and highly reactive forms of oxygen (24). Oxidative damage has been closely linked to skin diseases, including CD. Reactive oxygen species are involved in the pathogenesis of allergic reactions in the skin and trigger the induction and maintenance of cutaneous inflammation (24).

As AST is a potent antioxidant, it has important applications in the nutraceutical, cosmetics and food industries. It exhibits marked antioxidant activity, suggesting its potential in targeting a number of health conditions (25). AST has several essential biological functions, including antioxidative action against lipid peroxidation, protection against damage by UV light and reduction of the immune response (26).

The present study demonstrated anti-allergic and anti-inflammatory actions of AST in vitro and in vivo, respectively. The topical application of AST was found to suppress allergic reactions in a mouse model of DNFB-induced allergic $\mathrm{CD}$. The increases in ear thickness and weight were prevented by the application of AST (Fig. 2). Inflammatory hyperplasia, edema and spongiosis are recognized as the microscopic hallmark of inflammatory skin disease, including allergic contact and nummular dermatitis (27). In the present study, the topical application of AST effectively reduced inflammatory hyperplasia, epidermal spongosis, edema and mononuclear cell infiltration (Fig. 3). These results suggested that epidermal spongiosis, edema and inflammatory cell infiltration resulted in enlargement of ear thickness and weight, and that AST prevented these inflammatory reactions effectively in DNFB-induced CD.

Repeated application of DNFB induces T helper (Th)1 skewing inflammation in the skin (28). IFN- $\gamma$, the hallmark of the Th 1 skewing reaction of $\mathrm{T}$ cell, is responsible for the increased production of various cytokines and chemokines in the skin, including interleukin-1, TNF- $\alpha$, granulocyte macrophage colony-stimulating factor and macrophage inflammatory protein (MIP)-2, which results in marked infiltration of leukocytes (29). Skin contact with a specific allergen induces the release of TNF- $\alpha$, another Th1 cytokine, during the sensitization phase (1). Furthermore, TNF- $\alpha$ exerts a stimulatory effect on skin cells, resulting in the recruitment of leukocytes during the elicitation of a contact hypersensitivity response (30). In the present study, AST treatment effectively reduced the production levels of IFN- $\gamma$ and TNF- $\alpha$ in the inflammatory tissues (Fig. 4). These data suggested AST as an anti-inflammatory agent against the Th 1 skewing reaction, resulting in a reduction of inflammatory reactions, including hyperplasia and spongiosis and immune cell infiltration.

Mast cells are important in adaptive and innate immunity, and their functions in skin immunity have been reported (31). Several studies have demonstrated an increase in the density of mast cells at inflammatory sites, and they are noted to undergo degranulation to produce small-molecule chemical mediators, including histamine and $\beta$-hexosaminidase $(8,32)$. Mast cells affect the functions of keratinocytes and fibroblasts through the release of TNF- $\alpha$ or histamine, which act on keratinocytes and promotes their production of adhesion molecules, proinflammatory cytokines, chemokines and growth factors (33). Mast cells and their mediators, particularly histamine, induce the activation and proliferation of fibroblasts $(33,34)$. In addition, mast cells recruit neutrophils during $\mathrm{T}$ cell-mediated delayed-type hypersensitivity reactions through TNF- $\alpha$ and MIP-2 (35). In the present study, AST effectively reduced the density of mast cells and mononuclear cells (Figs. 3 and 5). In addition, treatment with AST significantly inhibited the release of histamine and $\beta$-hexosaminidase from the RBL-2H3 cells in vitro (Fig. 6). These data suggested that AST may contribute to alleviate ear swelling and hyperplasia due to its suppression of inflammatory reactions, including the infiltration of neutrophils, activation of keratinoctyes and proliferation of fibroblasts.

Taken together, the present study demonstrated the anti-inflammatory and anti-allergic actions of AST, in terms of histopathologic change, mediator release and cytokine production. These results suggested that AST has similar effects to the dexamethasone in restricting the Th1 skewing reaction, and that AST may be used to treat patients with CD, particularly in patients exhibiting side effects caused by steroid treatment.

\section{Acknowledgements}

This study was supported by the Basic Science Research Program through the National Research Foundation of Korea, funded by the Ministry of Education (grant no. 2011-0024355); a grant from the New Growth Engine Industry Division, Busan Metropolitan City (grant no. 2010-2012; and the Aquaculture Industry Division funded grant by the National Fisheries Research and Development Institute, Gangneung, Korea (grant no. RP-14-AQ-62). Dr Seong-A Ju was additionally supported by the Priority Research Center Program (2009-0094050) through the National Research Foundation of Korea.

\section{References}

1. Saint-Mezard P, Rosieres A, Krasteva M, et al: Allergic contact dermatitis. Eur J Dermatol 14: 284-295, 2004.

2. Cavani A and De Luca A: Allergic contact dermatitis: novel mechanisms and therapeutic perspectives. Curr Drug Metab 11: 228-233, 2010.

3. Kapsenberg ML, Wierenga EA, Stiekema FE, Tiggelman AM and Bos JD: Th1 lymphokine production profiles of nickel-specific CD4+ T-lymphocyte clones from nickel contact allergic and non-allergic individuals. J Invest Dermatol 98: 59-63, 1992. 
4. Shimada Y, Hasegawa M, Kaburagi Y, et al: Lselectin or ICAM-1 deficiency reduces an immediate-type hypersensitivity response by preventing mast cell recruitment in repeated elicitation of contact hypersensitivity. J Immunol 170: 4325-4334, 2003.

5. Natsuaki M, Yano N, Yamaya K and Kitano Y: Immediate contact hypersensitivity induced by repeated hapten challenge in mice. Contact Dermatitis 43: 267-272, 2000.

6. Askenase P, Van Loveren H, Kraeuter-Kops S, et al: Defective elicitation of delayed-type hypersensitivity in W/Wv and SI/SId mast cell-deficient mice. J Immunol 131: 2687-2694, 1983.

7. Dudeck A, Dudeck J, Scholten J, et al: Mast cells are key promoters of contact allergy that mediate the adjuvant effects of haptens. Immunity 34: 973-84. 2011.

8. Theoharides TC, Alysandratos KD, Angelidou A, et al: Mast cells and inflammation. Biochim Biophys Acta 1822: 21-33, 2012

9. Broide DH: Molecular and cellular mechanisms of allergic disease. J Allergy Clin Immunol 108: S65-S71, 2001.

10. Fuchs J,ZollnerTM,Kaufmann R and Podda M:Redox-modulated pathways in inflammatory skin diseases. Free Radic Biol Med 30: 337-353, 2001

11. Sharkey P, Eedy DJ, Burrows D, McCaigue MD and Bell AL: A possible role for superoxide production in the pathogenesis of contact dermatitis. Acta Derm Venereol 71: 156-159, 1991.

12. Finnen MJ, Lawrence CM and Shuster S: Inhibition of dithranol inflammation by free radical scavengers. Lancet 217: 1129-1130, 1984.

13. Senaldi G, Pointaire P, Piguet PF and Grau GE: Protective effect of $\mathrm{N}$-acetylcysteine in hapten-induced irritant and contact hypersensitivity reactions. J Invest Dermatol 102: 934-937, 1994.

14. Sur R, Nigam A, Grote D, Liebel F and Southall MD Avenanthramides, polyphenols from oats, exhibit anti-inflammatory and anti-itch activity. Arch Dermatol Res 300: 569-574, 2008.

15. Sakai S, Sugawara T and Hirata T: Inhibitory effect of dietary carotenoids on dinitrofluorobenzene-induced contact hypersensitivity in mice. Biosci Biotechnol Biochem 75: 1013-1015, 2011.

16. Fassett RG and Coombes JS: Astaxanthin: a potential therapeutic agent in cardiovascular disease. Mar Drugs 9: 447-465, 2011.

17. Campoio TR, Oliveira FA and Otton R: Oxidative stress in human lymphocytes treated with fatty acid mixture: role of carotenoid astaxanthin. Toxicol In Vitro 25: 1448-1456, 2011

18. Yasui Y, Hosokawa M, Mikami N, Miyashita K and Tanaka T: Dietary astaxanthin inhibits colitis and colitis-associated colon carcinogenesis in mice via modulation of the inflammatory cytokines. Chem Biol Interact 193: 79-87, 2011.

19. Suzuki Y, Ohgami K, Shiratori K, et al: Suppressive effects of astaxanthin against rat endotoxin-induced uveitis by inhibiting the NF-kappaB signaling pathway. Exp Eye Res 82: 275-281, 2006.

20. Izumi-Nagai K, Nagai N, Ohgami K, et al: Inhibition of choroida neovascularization with an anti-inflammatory carotenoid astaxanthin. Invest Ophthalmol Vis Sci 49: 1679-1685, 2008
21. Starr RC and Zeikus JA: UTEX - The culture collection of algae at the University of Texas at Austin. J Phycol 29 (Suppl): 1-106, 1993.

22. Kwak TW, Cha JY, Lee CW, Kim YM, Yoo BH, Kim SG, Kim JM, Park SH and An WG: Anti-inflammatory and antioxidant effect of astaxanthin derived from microalgae. J Life Sci 21: 1377-1384, 2011 (In Korean).

23. Matsuda H, Morikawa T, Managi $\mathrm{H}$ and Yoshikawa $\mathrm{M}$ : Antiallergic principles from Alpinia galanga: Structural requirements of phenylpropanoids for inhibition of degranulation and release of TNF-alpha and IL-4 in RBL-2H3 cells. Bioorg Med Chem Lett 13: 3197-3202, 2003.

24. Bickers DR and Athar M: Oxidative stress in the pathogenesis of skin disease. J Invest Dermatol 126: 2565-2575, 2006.

25. Guerin M, Huntley ME and Olaizola M: Haematococcus astaxanthin: applications for human health and nutrition. Trends Biotechnol 21: 210-216, 2003.

26. Lorenz RT and Cysewski GR: Commercial potential for Haematococcus microalgae as a natural source of astaxanthin. Trends Biotechnol 18: 160-167, 2000.

27. Machado-Pinto J, McCalmont T and Golitz L: Eosinophilic and neutrophilic spongiosis: clues to the diagnosis of immunobullous diseases and other inflammatory disorders. Semin Cutan Med Surg 15: 308-316, 1996.

28. Dearman RJ, Basketter DA and Kimber I: Characterization of chemical allergens as a function of divergent cytokine secretion profiles induced in mice. Toxicol Appl Pharmacol 138: 308-316, 1996.

29. Kobayashi Y: The role of chemokines in neutrophil biology. Front Biosci 13: 2400-2407, 2008.

30. Grabbe S and Schwarz T: Immunoregulatory mechanisms involved in elicitation of allergic contact hypersensitivity. Immunol Today 19: 37-44, 1998.

31. Gould HJ, Sutton BJ, Beavil AJ, et al: The biology of IgE and the basis of allergic disease. Annu Rev Immunol 21: 579-628, 2003.

32. Navi D, Saegusa J and Liu FT: Mast cells and immunological skin diseases. Clin Rev Allergy Immunol 33: 144-155, 2007.

33. Kanda $\mathrm{N}$ and Watanabe S: Histamine enhances the production of granulocyte-macrophage colony-stimulating factor via protein kinase Calpha and extracellular signal-regulated kinase in human keratinocytes. J Invest Dermatol 122: 863-872, 2004.

34. Jordana M, Befus A, Newhouse M, Bienenstock J and Gauldie J: Effect of histamine on proliferation of normal human adult lung fibroblasts. Thorax 43: 552-558, 1988.

35. Biedermann T, Kneilling M, Mailhammer R, et al: Mast cells control neutrophil recruitment during $\mathrm{T}$ cell-mediated delayed-type hypersensitivity reactions through tumor necrosis factor and macrophage inflammatory protein 2. J Exp Med 192: $1441-1452,2000$ 